\title{
ANÁLISIS DE LA MATERNIDAD SUBROGADA EN TABASCO DESDE LA PERSPECTIVA DE GÉNERO
}

\author{
C. Tania Moreno Rueda ${ }^{1}$ \\ Dr. José Antonio Morales Notario ${ }^{2}$ \\ Dra. Josefina De la Cruz Izquierdo ${ }^{3}$
}

Resumen: El proceso habitual de la maternidad a través de la cual una mujer se embarazaba con los gametos de su pareja y que en un término lindante a los nueve meses daba a luz, ya no es la única forma de concebir un hijo. En la sociedad actual, se han desarrollado nuevas tecnologías en el campo de la reproducción humana asistida, las cuales permiten mantener con vida el grupo o célula social universal como es la familia. Dentro de esas técnicas de reproducción se encuentra la maternidad subrogada, la cual acarrea el surgimiento de nuevas interpretaciones legales respecto a la maternidad, con la finalidad de respetar el derecho a la procreación y obtener razonamientos lógicos que permitan a personas con problemas de fertilidad o bien personas incapaces de gestar a un bebé, encontrar la vía idónea para ser papás. Esto es un punto importante que indica la existencia de nuevos retos para los juristas, los cuales deben ampliar su espectro respecto a la materia en estudio, debido a que se requiere, de una formación ética, humana y desde luego jurídica para abordar estos temas. En este artículo se examina la maternidad subrogada en Tabasco desde una perspectiva de género y los elementos jurídicos que integran esta figura, con un enfoque equitativo que permite visualizar y diferenciar los derechos del hombre, de la mujer y del niño. Esta técnica de reproducción humana está reconocida e instaurada en el Artículo 380 Bis y 380 Bis 2 del Código Civil para el Estado de

\footnotetext{
${ }^{1}$ Estudiante de la Licenciatura en Derecho de la Universidad Juárez Autónoma de Tabasco. taniamorenorueda@gmail.com

${ }^{2}$ Dr. en Derecho. Profesor Investigador de la Universidad Juárez Autónoma de Tabasco. Jamn3110@hotmail.com

${ }^{3}$ Dra. en Educación. Profesora Investigador de la Universidad Juárez Autónoma de Tabasco. Josefina.delacruz@hotmail.com
} 


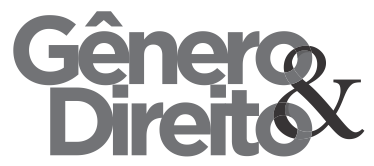

Tabasco, el cual es una guía para el adecuado desarrollo del tema.

Palabras Claves: Maternidad subrogada, Perspectiva de género, Derechos reproductivos, Derechos humanos.

Abstract: The usual process of motherhood through which a woman became pregnant with the gametes of her partner and that in a term bordering on nine months gave birth, is no longer the only way to conceive a child. In today's society, new technologies have been developed in the field of assisted human reproduction, which allow the maintenance of the universal social group or cell, such as the family. Within these techniques of reproduction is surrogacy, which leads to the emergence of new legal interpretations regarding maternity, in order to respect the right to procreation and obtain logical reasoning that allow people with fertility problems or People incapable of gestating a baby, finding the ideal way to be parents. This is an important topic that indicates the existence of new challenges for jurists, who must broaden their spectrum regarding the subject under study, because it requires ethical, human and, of course, legal training to address these issues. This article examines the surrogacy in Tabasco from a gender perspective and the legal elements that integrate this figure, with an equitable approach that allows to visualize and to differentiate the rights of the man, the woman and the child. This technique of human reproduction is recognized and established in Article 380 Bis and 380 Bis 2 of the Civil Code for the State of Tabasco, which is a guide for the proper development of the subject.

Keywords: $\quad$ Surrogacy, Gender perspective, Reproductive Rights, Human Rights.

\section{INTRODUCCIÓN}

Ingrid Brena Sesma (2012), define el derecho a la reproducción humana, como toda aquella expresión de la dignidad humana y del libre desarrollo de la personalidad, el cual se encuentra reconocido dentro del artículo $4^{\circ}$ constitucional, que señala en uno de sus párrafos: "Toda persona tiene derecho a decidir de manera libre, responsable e informada sobre el número y 




espaciamiento de sus hijos...", esto dado a

que quienes, en afán de dar continuidad a su genética, acuden a las modernas técnicas científicas que les ofrecen la oportunidad de tener descendientes, siendo una de estas técnicas de reproducción humana asistida "la maternidad subrogada".

Hay que tener en cuenta, que la intervención de la ciencia del derecho en la maternidad subrogada es de gran importancia, dado que la conducta del hombre, tiende a realizarse en una colectividad y deben existir leyes que regulen ciertas conductas, para lograr una adecuada convivencia, en la que se garantice el bien común de la sociedad. Aunque este artículo no pretende agotar la materia en estudio, también hace hincapié en la falta de especificidad en la regularización de esta técnica de reproducción humana en el estado y desde luego en la falta de control judicial en el proceso, lo cual no garantiza el respeto a los derechos humanos de las personas involucradas.

\section{DEFINICIÓN}

Maternidad sustituta, maternidad subrogada o alquiler de vientre son los nombres con los que se denomina dico do Núcleo de Estudos e Pesquisas sobre Gênero e Direito Centro de Ciências Jurídicas - Universidade Federal da Paraíba V. 6 - No 03 - Ano 2017 (Spanish Edition)

habitualmente a la práctica en la cual una mujer, previo acuerdo entre partes, se compromete a llevar adelante un embarazo y entregar al niño o niña fruto de ese proceso, en el momento del nacimiento o a los pocos días, a otra persona o pareja renunciando a sus propios derechos como madre (Arámbula Reyes, 2008).

Para entender el concepto definiremos primero que maternidad es esencialmente un vínculo jurídico entre madre e hijo, este vínculo acarrea una serie de derechos y obligaciones; subsecuentemente, definiremos que subrogación es la sustitución de una persona o cosa, obedeciendo el sujeto o el objeto al mismo régimen jurídico que el elemento al cual reemplaza (Enciclopedia Jurídica, 2014).

El Código Civil para el Estado de Tabasco en su Artículo 380 Bis define la reproducción humana asistida, como el conjunto de prácticas clínicas y biológicas para la creación de un nuevo ser humano, logrado mediante técnicas científicamente acreditadas y autorizadas por la legislación en materia de salud, realizadas con la intervención de personal de la salud, constituidas por métodos de fertilización de células germinales, gametos de uno o 


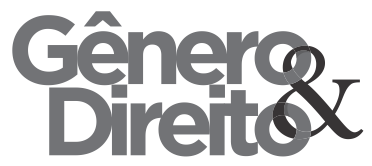

ambos sexos, además de la reproducción de cigotos y embriones, que permitan la procreación fuera del proceso biológico natural de la pareja infértil o estéril. También el Artículo 380 Bis 2 del mismo ordenamiento, nos menciona las formas de gestación por contrato, en las que se encuentra la gestación subrogada: la cual implica que la gestante sea inseminada aportando sus propios óvulos y que, después del parto, entregue el recién nacido a la madre contratante mediante adopción plena (H. Congreso del Estado, 2017).

La maternidad subrogada se puede presentar en las siguientes modalidades: como subrogación total, plena o tradicional, que consiste cuando la mujer contratada o bien la mujer que de manera gratuita acepta llevar el embarazo, es inseminada y ella proporciona sus propios óvulos, y que posteriormente después de la gestación y el parto, otorga el producto. Por lo general la inseminación se da con el esperma del padre comitente, pero también se puede realizar con la de un donante desconocido. La Subrogación parcial o gestacional consiste en implantar los gametos en la madre contratada por medio de la fertilización in vitro y en este caso se puede realizar con el óvulo de la madre comitente o la de una donante desconocida, pero no se realiza con un óvulo de la madre gestante, y el esperma se maneja la misma situación, el padre comitente o un donante.

Tomando en cuenta la finalidad, la gestación subrogada se puede dar del tipo altruista en la que la madre gestante acepta realizar este procedimiento de maternidad sin cobro alguno y por motivos de amistad, parentesco o amor hacia la pareja contratante; y se puede manejar de tipo onerosa en la que la madre gestadora se compromete a realizar este procedimiento a cargo de una contraprestación por parte de la pareja contratante para que al concluir el embarazo le entregue el producto de la concepción (Martínez Martínez, 2015).

\section{ANTECEDENTES}

Para entender la maternidad subrogada se debe analizar la historia y entender cuáles fueron los casos que la originaron, como por ejemplo dentro del Código del Rey Hammurabi que se originó en Mesopotamia en 1780 a. c existen diversas leyes que contemplan los 


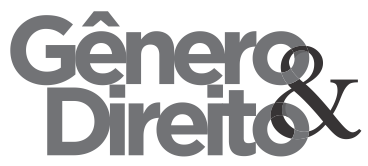

Periódico do Núcleo de Estudos e Pesquisas sobre Gênero e Direito Centro de Ciências Jurídicas - Universidade Federal da Paraíba V. 6 - No 03 - Ano 2017 (Spanish Edition) ISSN | 2179-7137 | http://periodicos.ufpb.br/ojs2/index.php/ged/index precedentes de este procedimiento, como la Ley 146 que disponía con referencia a las mujeres que eran estériles y quisieran tener hijos, podrían hacerlo dando una esclava a sus maridos para que procrearan y evitar así que el marido pudiera repudiarlas; a esta ley se anexaba la 147 que se refería a que si la esclava no conseguía embarazarse del esposo, la dueña podía venderla, y en la Ley 144 se especificaba que si la esclava dada al esposo lograba concebir hijos, el esposo era limitado y ya no podía buscar concubina. Y en la Ley 145 se observaba que si el esposo no lograba tener hijos de su esposa principal, ni recibía e ella esclava alguna, él tendría derecho a buscar una concubina y llevarla a su casa como esposa, pero en menor categoría que la principal.

Otro referente se encuentra en la India en las denominadas leyes de Manú, en donde acorde a la religión se prescribía que la mujer estéril fuera reemplazada después de ocho años; en la cultura hebrea en el libro del Génesis se relata la historia de Sarah que para darle un hijo a su marido Abraham le ofrece su sierva Agar que venía de Egipto, y la historia de Raquel que hacía lo mismo con su esclava Bilhá para que Jacob tuviera un hijo (Martínez Martínez, 2015).

Por otro lado, dentro de la cultura griega y romana se disponía en su religión que al tener un matrimonio sin hijos por esterilidad de parte del marido, un hermano o un pariente de éste debía sustituirlo teniendo la mujer que entregarse al escogido, y el hijo que naciera, era considerado del marido y continuaba su culto; en el Sur de África, en el pueblo de los Kgatla se acostumbraba que si la pareja no podía tener hijos, podía buscarlo encargándoselo a una mujer fértil.

Hay opiniones que determinan que los orígenes de la maternidad subrogada provienen del siglo $\mathrm{XX}$, pues es hasta 1940 que se crea por primera vez un banco de semen, y hasta 1994 se encuentran registros de la primera fecundación extracorpórea de embriones humanos, que se realizó por los biólogos John Rock y Meneen.

En Estados Unidos, se tiene conocimiento que hasta 1953 se presentaron los primeros embarazos con semen congelado y en 1978, se dio el nacimiento del primer niño por la fecundación in vitro, Luise Brown, lo cual 
fue un cambio en la salud reproductiva. Es hasta los años noventa, que se tiene conocimiento de la realización de una fecundación extracorpórea, que significa realizar una inseminación con el esperma del cónyuge (Martínez Martínez, 2015).

En México, fue el estado de Tabasco reconocido como el primero en legislar este tipo de reproducción humana asistida, por medio de su Código Civil, que maneja regulaciones referentes a la maternidad subrogada y maternidad sustituta; logrando darse debido a la reforma de 1997 que optó por sustentar los acuerdos de ambos tipos de maternidad bajo la figura del contrato.

En ese entonces dicho ordenamiento no contaba con las especificaciones sobre tales convenios y no se hallaba ningún apartado o reforma en la sección del código. Hubo modificaciones que permitían a los cónyuges emplear los métodos de reproducción que desearan para lograr concebir y tener descendencia, lo que generaba algunas presunciones como la de determinar que a los hijos nacidos de madre gestante sustituta, sólo podían ser reconocidos por el esposo comitente a menos que él lo desconociera o que un juez en sentencia ejecutoria determinara su reconocimiento por alguien más.

Debido a los diferentes casos que se sucedieron en el Estado por causa de las lagunas jurídicas que no las previeron, hasta enero de 2016 el Congreso del Estado de Tabasco emitió reformas al Código Civil adicionando el Capítulo VI que contenía los artículos 380 Bis 1 al Bis 7 que permiten regular y especificar los conceptos de ambos tipos de maternidad y generar los requisitos más favorables para realizar los contratos que les corresponden, con el fin de legislar apropiadamente referente a los padres comitentes, como a las madres sustitutas y los aspectos económicos y pautas de la concepción y entrega de los bebes para formalizar una adopción plena (Alonso Tosca, 2016).

Este tema resulta polémico porque a pesar de ser un avance tecnológico, es un procedimiento que implica la vida humana y la libertad de procreación y sus límites y debe considerar los puntos de vista ético, jurídico y social para lograr encuadrar los beneficios y apropiado aspectos involucrados para la sociedad. 


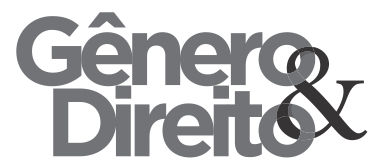

\section{DERECHOS REPRODUCTIVOS}

Los derechos reproductivos son la capacidad de todo hombre y mujer para decidir cómo y cuándo tener descendencia y que tiene base en su derecho de libertad de decisión sobre el número que deseen tener y el esparcimiento entre ellos y que se apoyan en los derechos humanos fundamentales como el derecho a la atención de la salud reproductiva y el derecho a la autodeterminación reproductiva o libertad de procreación. En este punto podemos definir que los derechos humanos son los derechos inherentes a nuestra naturaleza, parte de nuestra naturaleza humana y que no se pueden negar, pues se violenta la dignidad (Reyes Monjaras, 2008).

Por lo tanto, la reproducción se reconoce como un derecho humano por lo que, internacionalmente se han elaborado instrumentos que busquen la protección, promoción y defensa de los Derechos Humanos a los que se les ha denominado Derecho Internacional de los Derechos Humanos, en todos ellos se busca la protección de la familia, el libre ejercicio del derecho de contraer matrimonio y protección de las madres y sus embarazos
Cóco do Núcleo de Estudos e Pesquisas sobre Gênero e Direito Centro de Ciências Jurídicas - Universidade Federal da Paraíba V. 6 - No 03 - Ano 2017 (Spanish Edition)

y los niños y adolescentes, por ejemplo en la Declaración Universal de los Derechos Humanos se establecieron en el artículo 16 , el que determina que aquellas personas con edad suficiente para casarse pueden realizarlo y fundar una familia, siempre que sea por propio consentimiento y la sociedad y el Estado debe proteger a la familia; en el Pacto Internacional de Derechos Económicos, Sociales y Culturales se halla en el artículo $2^{\circ}$ y en el artículo 10; también en el Pacto de San José lo especifica en el artículo 17 y en la Convención Europea de los Derechos del Hombre y de las libertades fundamentales.

En México, al igual que en otros países, a partir de la Conferencia Internacional sobre Población, que se celebró en Teherán en 1968, la reproducción se concibió como un derecho de cada individuo que, se localiza en el párrafo tercero del artículo $4^{\circ}$ de la Constitución que se apoya en la igualdad y la libertad. Es un reconocimiento de la naturaleza instintiva y reproductiva del ser humano que busca determinarla como un derecho personal a unirse con fines de procreación y especificando su libertad de elegir el número de hijos a tener (Reyes Monjaras, 2008). 


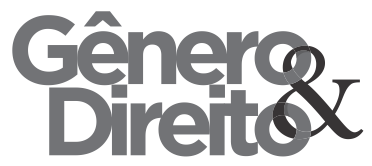

Dentro de los argumentos en contra de este procedimiento se hallan el que no afecta el derecho a la salud, pues él no procrear o ser estéril afecta la integridad psicosomática o salud de la persona y la fecundación no puede constituirse como una terapia; tampoco afecta su derecho a la autodeterminación personal, puesto que ello implica el que el individuo tome decisiones familiares sin que el Estado o terceros se inmiscuya, pero esto no implica el tener descendencia; referente al derecho a fundar una familia, este se ve dividido entre el derecho a reproducirse que no se puede ejercer cuando uno o los dos son estériles o no pueden tener hijos, y el derecho a mantener una vida de familia, que trae implícito la función procreativa que se puede enmarcar dentro del matrimonio o dentro de una relación de pareja de heterosexuales; en cuanto a la salud de la familia, este procedimiento se contrapone ya que la familia se halla en crisis y más el concepto de familia tradicional, que vio necesario la creación de diversas instituciones para reafirmar, consolidar y proteger este grupo social, que se ve afectado por divorcios, separaciones, papeles de la mujer cambiantes, liberaciones sexuales,
Céco do Núcleo de Estudos e Pesquisas sobre Gênero e Direito Centro de Ciências Jurídicas - Universidade Federal da Paraíba V. 6 - No 03 - Ano 2017 (Spanish Edition) permite democratizar este grupo y pide escuchar la opinión de todos los involucrados, incluyendo a los hijos; el derecho a la libertad de procrear también se somete a controversia, pues se cuestiona si es uno derecho individual o compartido y el cual se determina de acuerdo a si se trata de un varón o una mujer y que se determina que se maneja entre dos personas legalmente, no entre tres; el derecho a la libertad de procrear o reproducción en donde la restricción se conforma por las necesidades de los hijos nacidos o futuros y las obligaciones de los padres frente a la comunidad (Arambula Reyes, 2008).

La asociación TUDYSEX, en referencia al Estado de Tabasco presentó seis juicios de amparo con referencia a las reformas realizadas al Código Civil de Tabasco, ya que consideraron que violentaban el artículo $4^{\circ}$ constitucional el cual determina en su Artículo 399, fracción I, que la adopción plena puede realizarse solamente por varón y mujer casados entre sí o que vivan públicamente como marido y mujer, sin tener algún impedimento para contraer matrimonio entre sí. Esto da a entender que la 


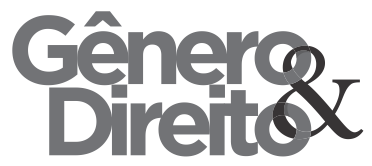

legislación civil tabasqueña no contiene en sentido amplio el derecho a la procreación, debido a que no menciona los derechos al libre acceso de este método de reproducción humana en cuanto a las personas del mismo género que están casados y que planean o desean tener un hijo por medio de la maternidad subrogada, así como tampoco menciona algún detalle respecto a las mujeres $u$ hombres que desean vivir en unión libre con su pareja y que no pueden concebir un hijo de la manera comúnmente conocida pero que por medio de este método, como es la maternidad subrogada puedan lograrlo, es decir el código no lo menciona como forma de permitirlo pero tampoco lo menciona para prohibirlo.

En este sentido la Suprema Corte de Justicia de la Nación dio a conocer una jurisprudencia, la cual entró en vigor el 30 de enero del 2017, que trata sobre el derecho a la vida familiar de las parejas del mismo sexo, la cual dice textualmente:

"a partir de las consideraciones del Tribunal Europeo de Derechos Humanos sobre la similitud entre las parejas homosexuales y heterosexuales en cuanto a su capacidad de desarrollar una vida fa miliar, la Primera Sala de esta Suprema Corte de dico do Núcleo de Estudos e Pesquisas sobre Gênero e Direito Centro de Ciências Jurídicas - Universidade Federal da Paraíba V. 6 - No 03 - Ano 2017 (Spanish Edition)

Justicia de la Nación entiende que la vida familiar entre personas del mismo sexo no se limita únicamente a la vida en pareja, sino que puede extenderse a la procreación y a la crianza de niños y niñas según la decisión de los padres. Así, existen parejas del mismo sexo que hacen vida familiar con niños y niñas procreados o adoptados por alguno de ellos, o parejas que utilizan los medios derivados de los avances científicos para procrear" (Suprema Corte de Justicia de la Nación, 2017).

Esto da a entender que el tema del derecho a la reproducción en la maternidad subrogada en Tabasco necesita ser más debatido con la intensión de encontrar solución a las lagunas existentes en el Código Civil de la misma entidad federativa antes mencionada, de ese modo lograr la protección total de los derechos humanos de las personas que desean ser papás mediante esta alternativa.

\section{DERECHOS DEL HOMBRE EN MATERNIDAD SUBROGADA}

Respecto a los derechos del hombre, el Código Civil para el Estado de Tabasco menciona que se requiere de una mujer que de su consentimiento para poder 


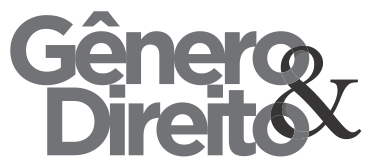

lograr la procreación por medio del contrato de gestación subrogada, en este sentido es complicado para el género masculino el libre derecho que tiene a la expansión de sus genes, de igual forma es difícil su acceso completo al respeto y protección a su derecho de no ser discriminado, así como, el derecho a la igualdad de condiciones que debe existir en el hombre y la mujer en lo que es su esfera reproductiva (H. Congreso del Estado, 2017).

Puede que en este sentido exista una contradicción en el Código Civil del Estado de Tabasco y la Constitución o bien un mal planteamiento del legislador respecto a los derechos que debe tener el hombre en la maternidad subrogada. Ya que el artículo $4^{\circ}$ de la carta magna dice que el varón y la mujer son iguales ante la ley. Esta protegerá la organización y el desarrollo de la familia y también menciona que toda persona tiene derecho a decidir de manera libre, responsable e informada sobre el número y espaciamiento de sus hijos (Cámara de Diputados del H. Congreso de la Unión, 2017).

$\mathrm{Si}$ bien el Código Civil de Tabasco no menciona en sentido amplio ódico do Núcleo de Estudos e Pesquisas sobre Gênero e Direito Centro de Ciências Jurídicas - Universidade Federal da Paraíba V. 6 - No 03 - Ano 2017 (Spanish Edition)

los derechos del hombre en la maternidad subrogada, tampoco los prohíbe totalmente, púes de algún modo otorga importancia a la voluntad de procrear, sólo que desde una perspectiva reducida ya que lo hace tomando en cuenta la institución del matrimonio entre personas heterosexuales y que ambas deben cederse consentimiento para poder tener un hijo por medio de la maternidad subrogada, en dado caso la mujer no cuente con el consentimiento del hombre para someterse a dicho procedimiento, esto será una causal para la disolución matrimonial $(\mathrm{H}$. Congreso del Estado de Tabasco, 2017).

En la regularización existente en Tabasco respecto a la materia en estudio queda claro que se requiere de una Ley exclusivamente para los métodos de reproducción humana asistida, en donde se garanticen y enfaticen los derechos que tienen en este caso el hombre que desee procrear un hijo sin la necesidad de contraer matrimonio, del hombre que esté casado con una persona de su mismo género, que quiera mediante esta técnica tener un bebé y por otro lado donde se mencione el derecho del hombre que dona sus espermatozoides y que no desea ser 


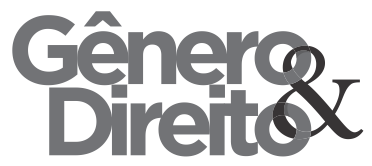

reconocido como padre del menor que nace mediante este método.

\section{DERECHOS DE LA MUJER EN LA MATERNIDAD SUBROGADA}

En épocas anteriores era fácil observar las constantes limitaciones que existían para las mujeres en diversos aspectos, en base al respeto a la igualdad en la actualidad se han reconocido los derechos que tiene la mujer, dentro de estos derechos se encuentra el derecho a tomar decisiones reproductivas de manera libre, informada y desde luego responsables, todo lo antes mencionado establecido en la carta magna (Reyes Monjaras, 2008).

\section{La mujer tiene un papel} importante y determínate en el proceso de la reproducción humana asistida, debido a que la procreación es una de sus capacidades fisiológicas indiscutibles e inherentes a su persona, además que la sociedad en la cual se ha desarrollado en este caso la mexicana, se preservó durante muchos años esta figura como parte de los valores familiares. Estos retos que se les han asignado a las mujeres y también a los hombres en el seno familiar
Códico do Núcleo de Estudos e Pesquisas sobre Gênero e Direito Centro de Ciências Jurídicas - Universidade Federal da Paraíba V. 6 - No 03 - Ano 2017 (Spanish Edition) 116 continuamente, un ejemplo es que a las niñas se les educaba y preparaba para ser madres y formar una familia con un hombre.

Con el paso del tiempo hasta la actualidad, la figura de la maternidad se puede ver desde diversos ángulos, esto porque que la clásica forma de concebir a un bebé, a través de la cual una mujer se embarazaba con los gametos de su pareja y que en un término lindante a los nueve meses daba a luz, ya no es la única forma de concebir un hijo. Dentro de estos nuevos panoramas y formas de concebirá a un menor y a los cuales las mujeres tienen derecho, se encuentran los métodos de reproducción humana, en este caso la maternidad subrogada. En la maternidad subrogada, la mujer puede ser la madre gestante o bien la mujer contratante que renta el vientre de otra mujer para tener un hijo. En este sentido el Código Civil para el Estado de Tabasco menciona algunos derechos más no específica el derecho de ambas mujeres, así como tampoco menciona claramente las obligaciones de la mujer que funge como madre gestante (Brena Sesma, 2012).

Un ejemplo de lo antes mencionado es que el mismo 


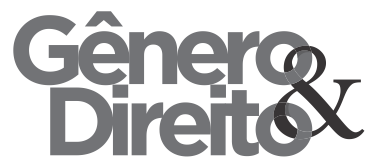

Periódico do Núcleo de Estudos e Pesquisas sobre Gênero e Direito Centro de Ciências Jurídicas - Universidade Federal da Paraíba V. 6 - No 03 - Ano 2017 (Spanish Edition) ISSN | 2179-7137 | http://periodicos.ufpb.br/ojs2/index.php/ged/index

ordenamiento, menciona en el Artículo 380 Bis 3 la condición de la mujer gestante en donde expone que La Secretaría de Salud del Gobierno del Estado determinará el perfil clínico, psicológico y social de la "madre gestante" previamente a su contratación, para comprobar que su entorno social sea estable, libre de violencia y su condición física y psicológica sea favorable para el adecuado desarrollo de la gestación (H. Congreso del Estado, 2017)

Así como también, establece que ninguna mujer que padezca alcoholismo, drogadicción, tabaquismo o alguna toxicomanía podrá ser contratada como madre gestante. Pueden ser contratadas como gestantes sólo las mujeres de entre veinticinco y hasta treinta y cinco años de edad que tengan una buena salud biopsicosomática y que hayan dado su consentimiento de manera voluntaria para ser gestante subrogada o sustituta, habiendo adquirido plena información acerca del proceso, previa a la manifestación de su consentimiento $(\mathrm{H}$. Congreso del Estado, 2017).

De igual forma dice que la gestante, para poder celebrar contrato en este caso de maternidad subrogada, deberá acreditar, mediante dictamen médico expedido por institución oficial de salud, que no estuvo embarazada durante los trescientos sesenta y cinco días previos a la implantación de la mórula y que no ha participado en más de dos ocasiones consecutivas en dicho procedimiento; lo que no impediría que pueda donar el óvulo para la fecundación in vitro o portar al producto fecundado en su vientre mediando conocimiento del cónyuge o concubino.

El Código Civil para el Estado de Tabasco ciertamente establece los requisitos que debe tener una mujer que quiera rentar su vientre o bien que decida a título gratuito tener un bebé para otras personas, porque en realidad este ordenamiento jurídico, no prohíbe que este método se pueda hacer a título gratuito, tampoco menciona los derechos que tiene la mujer que llevará acabo el embarazo mediante la maternidad subrogada respecto al niño, menciona por un lado el derecho de tener la custodia del bebé nacido en el caso de las mujeres que ejerzan el papel de madre sustituta que ciertamente forma parte del método de reproducción humana asistida pero que de acuerdo al mismo código y a otros 
ordenamientos jurídicos no es lo mismo la gestación sustituta a la gestación subrogada, por tanto este punto no está establecido (H. Congreso del Estado, 2017).

Otro de los derechos de la gestante que si regula el Código Civil Para el Estado de Tabasco es que podrá demandar a la madre y al padre contratantes por el pago de gastos médicos, en caso de patologías genéticas y las que deriven de una inadecuada atención y control médico prenatal y postnatal. Esto indica que se respeta el derecho a la salud de la gestante subrogada, pero no lo garantiza, pues no existe en el ordenamiento un artículo que obligue a los padres contratantes garantizar la salud a la madre subrogada con una póliza de seguro de gastos médicos mayores en el caso de padecimientos después del parto, el ordenamiento si dice que es una obligación de los contratantes, pero no dice el medio por el cual se garantiza el cumplimiento de esta obligación (H. Congreso del Estado, 2017).

Respecto a la madre contratante el mismo ordenamiento jurídico menciona los requisitos del contrato de gestación, donde estípula que la mujer contratante debe acreditar, mediante certificado médico expedido por el médico tratante de la institución acreditada, que posee una imposibilidad física o contraindicación médica para llevar a cabo la gestación en su útero y que cuenta entre veinticinco y cuarenta años de edad $(\mathrm{H}$. Congreso del Estado, 2017). En este sentido pone de ante mano que la mujer debe contar con ciertos requisitos, lo cual indica que se limita el derecho a la libre expansión familiar a las mujeres que están casadas con una persona de su mismo género y que desean por medio de este avance científico tener un bebé (Cámara de Diputados del H. Congreso de la Unión, 2017).

Con lo antes expuesto se conocen algunas de las lagunas que aún existen en el Código Civil del Estado de Tabasco, lo que ha generado diversos conflictos a las personas que han tenido un hijo por la vía de reproducción humana asistida como es la maternidad subrogada, por este motivo el congreso del Estado debe promover debates con la finalidad de mejorar el ordenamiento referente al tema o bien para mejorar el procedimiento mediante la creación de una norma exclusiva a la libre procreación de manera correcta por medio 


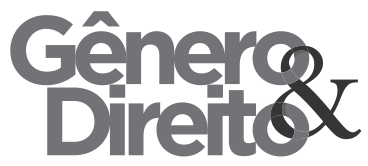

de esta técnica de reproducción humana asistida en el Estado.

\section{DERECHO DE LOS NIÑOS NACIDOS POR MATERNIDAD SUBROGADA}

Los avances tecnológicos y científicos van avanzando diariamente y de forma apresurada, esto ocasiona que los legisladores creen normas jurídicas de manera superficial y mal planteadas, lo que produce que no se protejan en su totalidad los derechos humanos de las personas, incluidos los niños que nacen por medio de esta técnica de reproducción humana como es la maternidad subrogada. La idea principal de los derechos humanos es que todas las personas, entre estas los niños, gocen de los derechos que el artículo primero de la carta magna estipula, además que es deber de todos los Estados promover y garantizar su firme protección desde una perspectiva de igualdad (Reyes Monjaras, 2008).

La Convención Internacional sobre los Derechos del Niño de 1959 existe con la intención de garantizar el desarrollo integral, procurar una vida digna, así como procurar las condiciones materiales $\mathrm{y}$
Cédico do Núcleo de Estudos e Pesquisas sobre Gênero e Direito Centro de Ciências Jurídicas - Universidade Federal da Paraíba V. 6 - No 03 - Ano 2017 (Spanish Edition)

afectivas idóneas que le permitan al niño vivir plenamente y de ese modo alcanzar el bienestar de las niñas, así como el de los niños (Organización de los Estados Americanos [OEA], 1959). Existen posiciones y puntos de vista que rechazan la práctica de la maternidad subrogada los cuales refieren, que con esta técnica de reproducción humana desde una perspectiva de contratos se ve al menor como un objeto, sin embargo se debe tener en cuenta que separando el encuadramiento del contrato, quien nace por medio de la maternidad subrogada es un niño que a la ves es una persona que es titular de derechos como cualquier otro ser humano, los cuales deben ser protegidos para que de ese modo ese niño goce de igualdad de la misma forma en que disfrutan otras niñas y niños (Reyes Monjaras, 2008).

En esa orden de ideas Tabasco requiere de la regularización especifica en su código civil respecto a la maternidad subrogada y en cuanto a la protección del interés superior del infante, el marco legal que regule esta técnica de reproducción humana debe brindar una seguridad jurídica, la cual permitiría que las personas que desean ser padres de un menor, puedan 


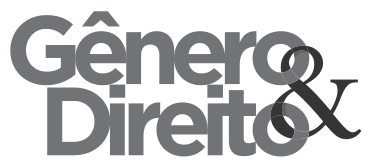

serlo de una manera segura. Todo menor nacido por la vía o técnica de reproducción humana como es la maternidad subrogada tienen derecho a la filiación tanto materna como paterna.

De este modo el Código Civil para el Estado de Tabasco establece que la filiación del niño o niña solo puede realizarse mediante la figura de la adopción plena y debe ser aprobada por el juez competente. Además el niño no tiene derecho de acuerdo a lo reglamentado, a conocer a la persona gestante, dado que esta persona debe renunciar a sus derechos como madre por medio del contrato de gestación subrogada. Otros aspectos que el código civil tabasqueño no tomó en consideración son el derecho del niño a su identidad en cuanto al conocimiento del modo en cómo fue concebido, a tener un entorno (H. Congreso del Estado de Tabasco, (2017).

Los niños que nacen por medio de la maternidad subrogada también tienen derecho a una educación plena, merece tener un crecimiento rodeado de amor y debe contar con plena autonomía sobre el ejercicio de todos sus derechos. En este sentido Tabasco al permitir la maternidad subrogada, debería establecer en su código
Códico do Núcleo de Estudos e Pesquisas sobre Gênero e Direito Centro de Ciências Jurídicas - Universidade Federal da Paraíba V. 6 - No 03 - Ano 2017 (Spanish Edition)

todas las pautas necesarias para la correcta protección del menor. El interés superior del niño exige tomarlo en cuenta como un ser humano, ya que él es un verdadero poseedor de derechos que deben ser respetados, tanto por los adultos como también deben ser respetados por el Estado ( [SCJN], (2016).

\section{CONCLUSIÓN}

Es entendible que la constitución establece que todas las persona pueden decidir libremente sobre su esparcimiento familiar o bien sobre la procreación, es decir tienen derecho a una paternidad o bien a una maternidad, es este sentido la persona pude decidir por tanto los medios por los cuales pueda alcanzar esta finalidad, el artículo $4^{\circ}$ constitucional debe ser interpretado en un sentido amplio para que por medio de esa interpretación lógica que surja, no genere problemas al momento de la creación de una norma Estatal, en este sentido seria la regularización correcta de a maternidad subrogada en el Estado de Tabasco.

Guzmán Ávalos (2001) menciona que el derecho a la procreación no puede quedar establecido solo para las 
personas casadas, sino que le pertenece a todos los mexicanos sin distinción de géneros. Por tal motivo es complicado tener una posición definitiva debido a que están en juego los derechos humanos inseparables a la personalidad y sobre todo el respeto que debe existir en cuanto a la vida de todas los involucradas o que sean parte de este método de reproducción humana, principalmente el respeto de toda la esfera jurídica del niño que nace por medio de esta técnica, con la finalidad de asegurar su correcto desarrollo humano.

Tabasco debe generar debates referentes a la maternidad subrogada en los que se propongan soluciones a las diversas lagunas jurídicas existentes en el Código Civil del Estado de Tabasco, ya sea que su finalidad sea reformar los artículos existentes en el cual especifiquen los derechos, las obligaciones de la madre contratante, madre gestante, del mismo modo los derechos, obligaciones de los padres varones contratantes y para el conyugue o concubino de la mujer gestante, así como lograr reglamentar la amplia protección a los derechos humanos del niño que nace mediante la maternidad subrogada o bien se sirvan para elaborar una Ley exclusivamente para la reproducción humana asistida en todas sus modalidades en donde se establezcan todos los lineamientos necesarios en los que se garantice la protección a los derechos humanos de las partes involucradas en la procreación mediante el método de la reproducción humana asistida "maternidad subrogada", principalmente que proteja el interés superior del niño, que de acuerdo a la Suprema Corte de Justicia de la Nación son la serie de valores, principios, interpretaciones, acciones y procesos dirigidos a forjar un desarrollo humano integral y una vida digna, así como a generar las condiciones materiales que permitan a los menores vivir plenamente y alcanzar el máximo bienestar personal, familiar y social posible ([SCJN], 2016).

\section{BIBLIOGRAFÍA}

Alonso Tosca, (2016). La maternidad subrogada y sustituta en el marco jurídico de Tabasco. Hechos y Derechos. UNAM. Recuperado en https://revistas.juridicas.unam.mx/index.p $\underline{\mathrm{hp} / \text { hechos-y- }}$ derechos/article/view/10480/12645 


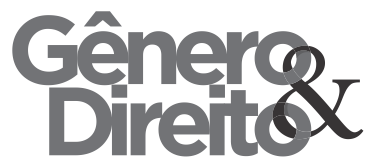

Arámbula Reyes, (2008). Maternidad subrogada, Centro de Documentación Información y

Análisis, Cámara de Diputados, LX Legislatura, México. Recuperado en http://www.diputados.gob.mx/sedia/sia/sp e/SPE-ISS-14-08.pdf

Brena Sesma, (2012). La gestación subrogada ¿Una nueva figura del derecho de familia? Biblioteca Jurídica Virtual del Instituto de Investigaciones Jurídicas de la UNAM. Universidad Nacional Autónoma de México. Recuperado en https://archivos.juridicas.unam.mx/www/ bjv/libros/7/3155/10.pdf

Cámara de Diputados del H. Congreso de la Unión, (2017). Constitución Política de los Estados Unidos Mexicanos. Recuperado en http://www.diputados.gob.mx/LeyesBibli o/pdf/1_240217.pdf

Enciclopedia Jurídica (2014). Edición 2014. Recuperado en http://www.enciclopediajuridica.biz14.com/inicio-enciclopedia$\underline{\text { diccionario-juridico.html }}$
González Contró, (2012). Los derechos del niño en la reproducción asistida. Biblioteca Jurídica Virtual del Instituto de Investigaciones Jurídicas de la UNAM. Universidad Nacional Autónoma de México. Recuperado en https://archivos.juridicas.unam.mx/www/ bjv/libros/7/3155/8.pdf

Guzmán Ávalos, (2001). Inseminación artificial y fecundación in vitro humanas. Un nuevo modo de filiación. México. Universidad Veracruzana. pp. 27-28.

H. Congreso del Estado de Tabasco, (2017). Código Civil para el Estado libre y soberano de Tabasco. Tabasco, México. Recuperado en http://a245249236eda49dcbd9$\underline{\text { 4febb582370306e21521643c4f578978.r9 }}$ 2.cf1.rackcdn.com/2014/orden1/Codigos/ Codigo\%20Civil\%20para\%20el\%20Esta do\%20de\%20Tabasco.pdf

Martínez Martínez, (2015). "Maternidad subrogada. Una mirada a su regulación en México", Dikaion, 24-2. DOI: 10.5294/dika.2015.24.2.7. Recuperado en 
Gônerger

http://www.redalyc.org/html/720/720458

$\underline{44007 /}$

Naciones Unidas [ONU], 1948.

Declaración Universal de los Derechos

Humanos. Recuperado en

http://www.un.org/es/documents/udhr/U

$\underline{\text { DHR_booklet_SP_web.pdf }}$

, (1976). Pacto

Internacional de Derechos Económicos,

Sociales y

Culturales. Recuperado en

https://www.colmex.mx/assets/pdfs/3-

PIDESC 50.pdf?1493133895

Organización de los Estados Americanos [OEA], (1981). Convención Americana sobre Derechos Humanos, San José de Costa Rica, Recuperado en https://www.colmex.mx/assets/pdfs/4-

CADH_51.pdf?1493133911

(1959). Declaración de los Derechos del Niño. ONU Doc. A/4354. Recuperado en https://www.oas.org/dil/esp/Declaraci\%C 3\%B3n\%20de\%201os\%20Derechos\%20d el\%20Ni\%C3\%B10\%20Republica\%20D ominicana.pdf
The law regarding the legal position of human reproduction in single women. UNACAR. Tecnociencia. 2(1)1-13. Recuperado en http://www.unacar.mx/contenido/tecnocie ncia/tecnociencia2/contenido2.pdf

Suprema Corte de Justicia de la Nación [SCJN], (2016). Adopción. El interés superior del menor de edad se basa en la idoneidad de los adoptantes, dentro de la cual son irrelevantes el tipo de familia al que aquél será integrado, así como la orientación sexual o el estado civil de éstos. Tesis Jurisprudencial 8/2016 (10a $\left.{ }^{\mathrm{a}}\right)$. Gaceta del Semanario Judicial de la Federación. Libro 34, Tomo I., p. 6 https://sjf.scjn.gob.mx/sjfsist/Paginas/Det alleGeneralV2.aspx?ID=2012587\&Clase $=$ DetalleTesisBL\&Semanario $=0$

(2017). Derecho a la Vida Familiar de las parejas del mismo sexo. Tesis Jurisprudencial 8/2017 (10a .). Gaceta del Semanario Judicial de la Federación. Libro 
Periódico do Núcleo de Estudos e Pesquisas sobre Gênero e Direito Centro de Ciências Jurídicas - Universidade Federal da Paraíba V. 6 - No 03 - Ano 2017 (Spanish Edition) ISSN | 2179-7137 | http://periodicos.ufpb.br/ojs2/index.php/ged/index

38, Tomo I, p. 127. Recuperado en

https://sjf.scjn.gob.mx/sjfsist/Paginas/Det

alleGeneralV2.aspx? ID=2013531\&Clase

$=$ DetalleTesisBL\&Semanario=0\# 